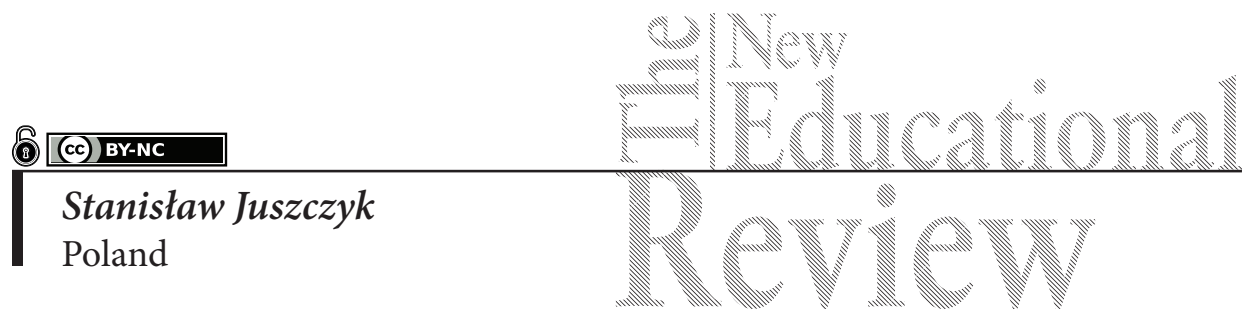

\title{
A Role of Critical Questions in Preparing a Scientific Article
}

DOI: 10.15804/tner.2018.54.4.21

\begin{abstract}
The article discusses a hermeneutical analysis of academic texts related to the methodological criticism of individual elements of the structure of designed quantitative research, published in the form of articles, chapters in collective works and monographs. Dilemmas of researchers constructing research projects, asking themselves critical questions at each stage of a research procedure, will be described, critical situations for the correctness of a research process, and also general methodological requirements of scientific publications will be indicated. Besides the description of a critical approach of chosen researchers, the work also includes the author's reflections on carrying out empirical research.
\end{abstract}

Keywords: scientific criticism, critical questions, hermeneutical analysis

\section{Scientific criticism}

The term 'scientific criticism', which is useful in our discussion, is being a science-based analysis and assessment of scientific works in terms of their cognitive value and practicability as well as formal correctness (logical scientific criticism). We can analyse cognate words connected with 'scientific criticism', e.g., in terms of substantive compliance with the established facts (empirical scientific criticism); legal validity and the correctness of used methods (methodological scientific criticism); the assumed purpose and scientific concepts (theoretical scientific 
criticism) and in terms of philosophical assumptions (philosophical scientific criticism). It turns out that 'scientific criticism' or 'research criticism' are terms that are often used in the world's methodological literature and, furthermore, also other terms can be found in it such as: critical analyses, review/commentary/checking, evaluation and assessment (c.f., CyberNurse, 2005). Therefore, methodological scientific criticism is related to: critical analysis of theories describing a given occurrence or process; critical assessment of the results of research published by various authors in the form of monographs, articles and conference papers; critical analysis of the source literature containing both theoretical bases for research, and its sample results; criticism of methodological concepts of designed basic and applied research (critical analysis of the research structure); critical assessment of Master's, doctoral, and postdoctoral dissertations (academic promotion papers in general); critical analysis of individual and team, national and international scientific research projects submitted for assessment; critical analysis of proposed research methods, techniques and tools; critical analysis of the results of empirical research; critical assessment of the use of statistical techniques and tools; and critical assessment of the conclusions from research and proposals for putting into practice. The term of methodological scientific criticism is therefore very broad-ranging, wide, it covers analysis of many other terms, research methods and activities undertaken by researchers when designing, realising, and preparing research results.

An ability to critically evaluate individual elements of a research procedure (especially in research carried out in the positivist paradigm) is a necessary skill of researchers from different scientific disciplines, in order to assess the integrity and usability of research results and conclusions formulated. Research criticism is a mechanism that enables to repeat research in order to confirm the reliability of the results obtained, and even to collect further information (D.F. Polit, C.T. Beck, 2006). In general, the ability to critically evaluate a research procedure is automatic for many experienced researchers having considerable knowledge and skills in the methodology of research, whose skills cover the following: identifying the object of research, formulating the objectives of research, research questions and hypotheses, selecting a survey sample, constructing a research project, verifying the established research procedures and developed tools, gathering data and analysing data, using statistical methods and tests, and interpreting the results obtained. Without an objective interpretation of obtained data, breakthroughs in science and the development of science would be impossible. The driving force of fact-based research, in a traditional sense, is an ability to measure and assess an occurrence (its quantification), and also relations between occurrences, regard- 
less of the nature of these occurrences (D.E. Vance et al., 2013, p. 67). Such an ability makes it possible to formulate particular research questions and verifiable hypotheses so that statistical procedures can be applied to the data obtained for the purpose of reducing them to discrete sets and including their specific areas; this process is often referred to as a reduction and is one of the objectives of science (D.H. Voelker, P.Z. Orton, 1993). From such sets, one may derive objective interpretations which, after some time, together with interpretations of other authors studying the same occurrences may allow for drawing conclusions for putting into practice, and may furthermore cause posing further research questions, and finding answers to them through further research may bring benefits both for science and practice.

The result of critical evaluation of research results described in academic literature, required from researchers, is the continuation of many improved practical activities related to putting research results into practice and modernising research methods and techniques. Hence, critical assessment of research results being described in the literature of a given scientific discipline or sub-discipline is so significant. Proceeding this way should be natural for all researchers, who should keep trace of the publication of the latest research in an area in which a given researcher or a given group of researchers is interested, verify the devised structures of a research process, and also their results and discussion in order to get to know the latest model of an explored occurrence. Proceeding this way should be accepted by junior research workers, for whom studying literature systematically and frequently plays a significant role in developing habits that are necessary for achieving scientific professionalism. For this reason, it is required that the theoretical basis for designed quantitative scientific research includes critical analysis of theories describing an occurrence being studied and of the latest results of other authors' research. Unfortunately, we may rarely encounter such critical analyses of the results of someone else's research in academic publications, articles more often only discuss selected results of such research and descriptions of those aspects of a theory which the authors are going to use when interpreting their own results. Research procedures are analysed selectively, in order to gain information, e.g., about the method of selecting a survey sample, or the specificity of the field of research. It is rare to find another article by the same author or by the same team that carried out their research again and obtained the same (or similar) results (performed auto-replication), confirming thereby the reliability of their research. Reliable scientific research has a capacity of being carried out again, i.e., a capacity of being replicated in order to make sure whether or not the regularities, dependencies, relations and courses observed are a repeatable course 
of an occurrence, process or event. Thus, obtaining similar (within the limits of a permissible error) research results by the same or other team of researchers, also individual researchers under different field conditions, on a different sample is confirmation of its reliability.

An ability to critically evaluate the results of someone else's research allows a researcher to avoid traps, errors or simplifications and is a good way of improving their own research technique and of honing their own research and methodological skills, leading to achieving professionalism (S. Juszczyk, 2011, pp. 17-32).

\section{The title and content of a scientific article}

When publishing research results, we need to pay attention to the title of an article or monograph. It should illustrate both the researcher's concept and the object of research, the data collection methods used, and include dependencies between variables and be comprehensible and not too lengthy at the same time. As the titles of scientific works not always fully illustrate the core of research, keywords are introduced in order to make it easier for the readers to determine dependencies being analysed, determine the usefulness of research and to place it in a specific area of scientific cognition.

\section{Critical questions and finding by a researcher the constructive answers in quantitative research procedure}

A quantitative, positivist approach is adopted when a researcher starts designing research with a critical analysis of a theory (or hypothesis) describing an occurrence and falsifies the hypothesis by getting confirmation of its rightness or rejection at an adopted level of confidence.

In qualitative research, a researcher pays attention to the context of an occurrence and social and cultural aspects of an environment being studied. Research questions are more open and wider, less precise and hypothetical. A wider spectrum of subjects, of different ethnic origin, race, language, social class, age, and also of a different social rank, is used as compared to a sample selected in quantitative research, which is more homogeneous.

Preparing to conduct research, and then to publish it, a researcher needs to pose a number of critical questions to which they should find constructive answers. One can meet elements of methodological scientific criticism discussed below in 
research projects prepared by individual researchers or scientific teams, and also in academic articles and monographs. The first element of scientific criticism is the question about the cognitive objective of research: Is this research necessary? What can it contribute to the scientific discipline and practice? Will it broaden the knowledge about an occurrence? If the answers are negative, this means there is no need to carry out this research. Further questions should concern a research project itself, based on the source literature, e.g.: Is there a theory describing the occurrence being studied? If there is none, will the researcher manage to collect data, and then to interpret them? Who will be subject to the research? What will be the structure of planned research? (cf., K. Carter, 2006; S. Valente, 2003, pp. 130-142).

The next element of research criticism is related to critical analysis of the literature, concerning the object of research. The questions the researcher should ask themselves could be the following: Is the review/analyse of the literature sufficient to design reliable research? Is the literature being analysed up-to-date (published in the last five years)? Are primary or secondary sources used? Is the review of the literature edited well, does it have introduction and summary, so was the latest model of the explored occurrence drafted? The researcher should also answer the following question: What has been written about the issue being studied so far?

A further stage of a critical look at research includes formulating research questions and hypotheses. This stage of scientific criticism is the most important because it is directly related to the objective of research. Most frequently, complementary questions are framed, such as: who, what, when, where, why and how? The researcher should think whether or not the questions are framed clearly? Do they contain the objective of research in them? (cf., C. Boswell, S. Cannon, 2011, p. 294).

Hypotheses should contain assumed relations between variables. Here, it should be mentioned that quantitative research should be designed so as to foresee using statistical methods for preparing the results of research and for falsifying hypotheses. A hypothesis may be defined 'as an assumption, a simple statement about predicted relations between variables' (D.F. Polit, C.T. Beck, 2006, p. 501). Simply speaking, a hypothesis may predict, suggest, assume, explain or verify the quality, property or feature of people, things or of an environment. We often use the phrase of 'hypothetical situations' in colloquial language, i.e., a hypothesis proposes a solution to a research problem, is a hypothetical answer to a research question, and the researcher formulates a hypothesis at a certain level of likelihood. Before formulating hypotheses, the researcher should ask themselves the following questions: Did they describe all of the most important variables? Did they perform their operationalisation, i.e., indexation? (after all we place variable indicators in 
research tools often constructed by the researcher) Are the hypotheses formulated clearly? Do the hypotheses illustrate the objective of research? (cf. C. Boswell, S. Cannon, 2011, p. 295)

Finally, we are reaching selection of research methods and techniques (data collection) that determines the way of framing research questions and their substantive content. The primary research problem determines the choice of the principal research method or technique, and detailed research questions may indicate the need to employ further research methods or techniques, which help the researcher collect data. Research methods and/or techniques may be quantitative or qualitative in nature, resulting in designing research that is mixed in nature, i.e., it can be quantitative-qualitative or vice versa. The researcher should answer the following questions: Did they choose research methods/techniques well? Are the research tools related to them of standardised nature (i.e., were constructed by other researcher and were standardised in specific research into an occurrence; they have to be used without the researcher's interference; sometimes, however, the researcher adapts some standardised tool to their needs, but they need to explain in detail and substantively their interference in the tool's structure and contents) or they were developed by the researcher themselves? How many times were the tools used to collect data and how long did it take? Are the tools still up-to-date and reliable? What is a sequence in which the researcher should use these tools (i.e., what are the stages of research)? (cf., N. Burns, S.K. Grove, 2001).

The next step in the research procedure is selecting a sample subject to research. In connection with this, the researcher poses the following questions: What population is the objective of research? How should a survey sample be selected: at random or purposefully/intentionally? What units should be a part of the sample: adults, teenagers or children, women, men, etc.? How big should a sample be, and what is the size of a sample selected for research? Can a selected sample be acknowledged to be representative (i.e., such in which the distribution of a selected variable is similar to its distribution in the population) for the general population (the size of the population itself is important)? The researcher should describe in detail the process of random or intentional selection of a sample because selecting a sample is a critical stage in designing research. To empirical research, specific people functioning under specific conditions are subject, and a change of the specificity of these people and research conditions may distort the image of explored dependencies or make it less clear. For this reason, repeating research into an analysed dependency many times, using various samples and research methods enables to eliminate errors, distortions, and, e.g., to eliminate a random error or an error coming from the size of a sample. 
The next stage is collecting data with the use of various research tools, tabulating them and presenting them graphically and statistically, falsifying hypotheses, a qualitative discussion and drawing conclusions. The researcher asks themselves, e.g., the following questions: What should be the sequence in which to collect data? What tools will be used? Should the next tools have been modified after analysing the data obtained earlier? What tools were used? Were they constructed properly and were reliable data obtained with the use of them? What statistical techniques were used in data analysis? Were the value of a statistical test and the size of an assumed error given? Were statistical conclusions drawn properly? What was the level of confidence at which analyses were carried out? Does the narrative, e.g., concerning political, sociological or pedagogical sciences capture the research results properly? Is it coherent, does it include objective argumentation and does it refer to all the data obtained? (cf., B. Holder, 2003). In a number of publications, the statistical significance of a link between variables is considered a measure of successful replication of scientific research. However, e.g., R. Rosenthal (1991) proves that this is not the statistical significance that is an indicator of successful replication, but some effect indicator, such as Cohen's $d$ statistics (a difference between the means divided by common standard deviation of both groups) or Pearson's $r$ correlation coefficient.

Finally, there comes a time of formulating answers to research questions. Criticism of this stage of research aims at answering the following questions: Were all the research questions answered? Were the answers complete and exhaustive? Does it have a close link to the correct structure of research tools, selection of a sample and the researcher's correct procedure in the field? Were limitations concerning the interpretation of the conclusions drawn from the research determined? Was generalising the conclusions from a representative sample for the general population successful? Do the conclusions drawn fall into the theories that were used to design the research? Were unexpected results obtained and how can the results be interpreted? (cf., L. Daggett, B.L. Harbaugh, L. Collum, 2005, pp. 255-258)

The last stage of scientific methodological criticism are recommendations concerning putting selected conclusions from the research into practice, determining the need to continue the research, indicating its further areas, or alternatively, finding a new field of research, survey samples, research methods and techniques, seeking further correlations, dependencies, concerning specifying the course of an occurrence or process. In connection with the above, the researcher poses the following questions: Are the research conclusions that the researcher is proposing to put into practice relevant for recipients? What positive changes in the course of an occurrence can one expect owing to them? What contribution to a scientific 
discipline or sub-discipline did the research make? What is the further research that should be designed and carried out? (cf. C. Boswell, S. Cannon, 2011, p. 296).

\section{Conclusions}

Methodological scientific criticism is aimed at eliminating errors in the procedure of designing research, makes it easier to construct reliable research tools, carry out research properly, carry out right quantitative and qualitative analyses of research results, and then to draw conclusions and formulate recommendations for putting them into practice. Criticism reveals both strengths and weaknesses of a research project, indicates specific activities for improving the quality of research, broadens the knowledge about an occurrence and demonstrates the need to explore the next aspects of an occurrence or process (B.L. Rodger, 1997).

The process of methodological scientific criticism leads to an intense verification of each stage of a research process. Criticism of a research process is necessary both during the process of designing research, and during the process of collecting data, verifying and interpreting them because different epistemological and methodological traps await the researcher.

\section{References}

Boswell C., Cannon S. (2011). Introduction to Nursing Research: Incorporating Evidence Based Practice, $2^{\text {nd }}$ ed., Critique process, chapter 13. Sudbury, Massachusetts: Jones \& Bartlett Learning.

Burns N., Grove S.K. (2001). The Practice of Nursing Research: Conduct, Critique, and Utilization ( $4^{\text {th }}$ ed.). Boston: Jones and Bartlett Publishers.

Carter K. (2006). How to Critique Research [Online, course materials]. Available at: http// www.runet.edu/ kcarter/CourseInfo/nurs442/chapter12.htm (22.03.2016).

CyberNurse (2005). Reading and critiquing research [online]. Available at: http://www. cybernurse.org.uk/research/reading_and_Critiquing_Research.htm (20.02.1018).

Daggett L., Harbaugh B.L., Collum L. (2005). A Worksheet for Critiquing Quantitative Nursing Research. Nurse Educator, 30(6), pp. 255-258

Holder B. (2003). The Research Critique [Online]. Available at: http://virtual.clemenson,edu/group/odce/summer1_03/nursT807/pdf. (24.04.2015).

Juszczyk S. ( 2011). The scientific development of the researcher in the process of shaping his scientific identity. "The New Educational Review", Vol. 26 (4), pp. 17-32.

Polit D.F., Beck C.T. (2006). Essentials of nursing research: Methods, appraisal, and utilization ( $6^{\text {th }}$ ed.). Philadelphia: Lippincott Williams \& Wilkins. 
Rosenthal R. (1991). Replication in behavioral research. In: J.W. Neuliep, ed., Replication Research in Behavioral Sciences, 1-30. Newbury Park, CA: Sage Publications.

Rodger B.L. (1997). Guidelines for Critique of Research Reports [Online, course materials]. Available at: http://www.uwm.edu/ brodg/Handout/critique.htm. (24.04.2016).

Valente S. (2003). Critical Analysis of Research Papers. Journal for Nurses in Staff Development, 196(3), pp. 130-142.

Vance D.E., Talley M., Azuero A., Pearce P.F., Christian B.J. (2013) Conducting an article critique for a quantitative research study: perspectives for doctoral students and other novice readers, Nursing Research and Reviews, 3, pp. 67-75.

Voelker D.H., Orton P.Z. (1993). Cliff's Quick Review of Statistics. Lincoln: Cliff Notes. 